\title{
Study on the Collaborative Innovation Oriented SDN Enterprise Ecological Collaboration Model
}

\author{
Li Chen \& Fuyuan Xu \\ Business School, University of Shanghai for Science and Technology, Shanghai 200093, China \\ E-mail: dalianchenli@126.com
}

Received: January 11, 2010 Accepted: February 13, 2011 doi:10.5539/ibr.v4n2p112

\begin{abstract}
By comparing the similarities between SDN (Supply and Demand Network with multifunctional and opening characteristics for enterprise) and natural ecosystem, the ecological characteristics of SDN enterprise are summarized in this article. The relationship among biological species groups in the natural ecosystem is used to describe the relationships of SDN enterprise in the collaborative innovation, and the collaborative innovation model among SDN enterprises based on the biology is generalized. In addition, four kinds of collaborative innovation oriented SDN enterprise ecological collaborative models are expounded respectively in detail.
\end{abstract}

Keywords: SDN enterprise, Collaborative innovation, Biology, Collaboration model

\section{Introduction}

The cooperation and win are the targets of the supply and demand network with multifunctional and opening characteristics for enterprise (SDN), and in the whole world, its target is the acquirement of the sources in the whole world, the manufacture in the whole world, and the distribution in the whole world, and the supply and demand network structure with multiple functional and opening characteristics will be formed among relative enterprises because of the interactive function of "supply and demand flow", with many characteristics such as networking, multifunction, sufficient opening, and dynamic stability (Xu, 2002, P.19-22). SDN enterprise collaborative innovation means that enterprises fully utilize the asymmetries of the SDN nodes (such as enterprise, enterprise alliance, and economic man) in the core business, the knowledge structure, and innovational skills, with the help of various networking collaborative work environments, innovational design tools, and knowledge integration means, to complement innovational advantages each others, provide innovational products and services, stimulate and enhance the total innovational ability of SDN, and realize the cooperation and win in the whole world, by various multi-layer collaborations of supply and demand flow (Chen, 2011).

SDN is the node set with complex network structure based on many supply and demand relationships, and SDN enterprise is one of common SDN nodes, and is the minimum node unit with independent operation ability. The multiple characteristics of SDN enterprise determine that SDN enterprises would have many different collaboration modes in the collaborative innovation. Because there are many similarities between SDN enterprise and natural ecosystem, it is very important to utilize the ecological idea to study the SDN enterprise collaborative innovation mode, support the collaborative innovation process, and enhance the collaborative innovation effect.

\section{Biological characteristics of SDN enterprise}

The concept of ecosystem was first proposed by British botanist A. G. Tansley in 1935, and it meant the dynamic compound formed by material circulation and energy flow, with reciprocity, interdependency, and self-organization function, in the biological population and interactive natural environment (Bai, 2007, P.174-178). In the long-term evolution of biological populations, many relationships such as predation, competition, autoeciousness, intergrowth, and reciprocity would respectively form among different biological populations. As viewed from the ecology, SDN enterprises would form SDN according to certain structure, with many similarities with the natural ecosystem, but it is an artificial ecosystem. Table 1 shows the comparison between the natural ecosystem and the SDN artificial ecosystem from structure and characteristic (Xu, 2006, P.97-100).

Because SDN has many similar characteristics with the natural ecosystem, the research method of the natural ecosystem could be used to study the SDN enterprise collaborative innovation mode.

\section{SDN enterprise collaborative innovation model based on the biology}

SDN is an artificial ecosystem, and it could use the relationship among biological populations in the natural ecosystem to describe the relationship among SDN enterprises in the collaborative innovation system, and 
summarize the collaborative innovation model among SDN enterprises based on the biology, as seen in Table 2 .

By using the division mode of the biological populations to analyze the enterprise relationship in the SDN enterprise collaborative innovation, and eliminate the situations without collaborative innovation among SDN enterprises (such as interior collaboration, independent innovation, and exclusive innovation), four SDN enterprise collaborative innovation models such as the homogeny strengthened model, the heterogeneous complementary model, the single-directional dependence model, and the multi-directional interaction model could be identified.

\section{Analysis of the collaborative innovation oriented SDN enterprise biological collaboration model}

\subsection{Homogeny strengthened model}

In SDN, homogeneous enterprises mean those enterprises which could produce like products or provide like services, and they all face same market, and similarly use limited production resources, so they have indirect limitation relationship among them. Because of different inborn conditions of homogenous enterprises, such as enterprise scale, human resource, and capitals, the core abilities of enterprises are obviously different, so SDN enterprises would be at different biological niches. The biological niches mean the resource demand capacity and core business ability of SDN enterprise according to the environment. The difference of the SDN enterprise biological niches and the limitation of the resource and market would produce the collaborative innovation drive of SDN enterprise, and many homogeneous enterprises with high biological niche occur, with strong core business ability, and to keep the exclusive advantage of the core business ability, realize the sustainable development of enterprise, and seek the innovational breakthrough of development, they will enhance the biological niche by the collaborative innovation. Those SDN enterprises with lower biological niche will strengthen the innovation pressure because of the competition effect, and to survive and development, they must separate them from the lapped biological niche and seek higher biological niche, which will also promote many SDN enterprises to improve the quality of product and service and enhance the core business ability by the collaborative innovation. Based on the concept of cooperation and win-win, homogeneous enterprises would not acquire the route of existing biological niche by traditional drastic competition, and they would create layered different biological niches by the collaborative innovation, and reduce the competition in the limited market resources, and strengthen the whole collaborative innovation capacity.

\subsection{Heterogeneous complementary model}

The heterogenic characteristic of SDN enterprises determines that two or more enterprises belong to heterogeneous enterprises. There are two kinds of relation among heterogenic enterprises. The first one is the collaborative function among SDN enterprises because of the business flow, with the direct upstream and downstream relation between supply and demand, by which enterprises would have close relation, and depend on each other. The other one is the direct association among enterprises without the relation between supply and demand, by which enterprises would have incompact association through multiple transfers of the relation of supply and demand. Usually, the former instance would exist in heterogenic enterprises. The formation of the supply and demand relation among SDN enterprises is a continually attempting and adjusting process, and according to the demand of the market, SDN enterprises would form relatively stable supply and demand network gradually through long-term selections. Heterogenic SDN enterprises have multilateral dependences, and though the multilateral dependences will change dynamically, but to sustain the relatively stable supply and demand relation, SDN enterprises will keep various collaborations with the cooperative enterprises. Innovation is the necessary selection for each SDN enterprise in the operation to keep the core ability, and when certain one enterprises in the supply and demand network begins to innovate, the cooperative heterogenic enterprises will also develop the collaborative innovations as viewed from the business complement to complement of innovational resources and results and keep relatively stable supply and demand relation.

\subsection{Single-directional dependence model}

Single-directional dependence-type SDN enterprise collaboration innovation model is a kind of asymmetric innovation, and a kind of parasitic behavior model. Whether for homogeneous enterprises or for heterogenic enterprises, one party in the cooperative enterprises (host enterprise) could not exclusive occupy the innovational result after investing innovational resources and acquiring innovational result, and because of the demand of the collaborative business, it will share the innovational result with the other party (parasitic enterprise) without paying for innovation, so the parasitic enterprise would have single-directional dependence to the host enterprise. Host enterprise and parasitic enterprise many be homogenous enterprises, or heterogenic upstream and downstream enterprises, and the single-directional dependence relation is a kind of special integration collaboration in essential, and the parasitic enterprise utilizes the innovational result application of the host enterprise to acquire extra income, and the share of the income will reduce the income of the host enterprise. In SDN, the single-directional dependence relation is only the short-term relation, and the collaborative innovation is the positive function behavior to promote and influence each other, and the negative function of the parasitic relation would reduce the innovation drive of the 
host enterprise. At the same time, the host enterprise could not ignore the division of the parasitic enterprise for the income, and to reduce the flow of the income, it would eliminate the parasitic enterprise and seek new supply and demand relation, and the parasitic enterprises in the innovational disadvantage must continually enhance the innovational ability and provide the innovational result which can be shared, to keep the relation of collaborative cooperation. Therefore, the single-directional dependence relation may break up, or change to the intergrowth collaboration relation or the multi-directional interaction relation.

\subsection{Multi-directional interaction model}

The multi-directional interaction model means that SDN enterprises with multiple supply and demand relationships have a kind of interdependent and mutually promoted ecological structure in the collaborative innovation, and based on the division and cooperation, they can realize the value increment which could not be realized by single enterprise by the collaboration of various supply and demand flows. The enterprises with multi-directional interaction innovation have certain dependence relationship, and they need sufficient communication, and they should respective contribute and share their own stage achievements, and support the collaborative innovation, and the deficiency of any one part would delay the collaborative innovation course and fail the collaborative innovation.

\section{Conclusions}

Based on the similarities between the SDN and the natural ecosystem, the ecological ideas are used to summarize the ecological characteristics of SDN enterprises, and describe the relationship in the SDN enterprise collaborative innovation process by the help of the relationship among biological populations. Four kinds of SDN enterprise ecological collaborative model facing collaborative innovation are expounded in detail, and the research result of this article could be used to instruct the collaborative innovation for SDN enterprises to some extent.

\section{References}

Bai, Zhiyong. (2007). Thinking about the Ecosystem Characteristics Based on Systems Science. Journal of Central South University of Forestry \& Technology. No. 12(6). P.174-178.

Chen, Li \& Xu, Fuyuan. (2011). Research on SDN Enterprise's Collaboration Innovation Mechanism. Asian Social Science. No.1.

Xu, Fang \& Li, Can. (2006). The Ecological Study on Industrial Cluster. Ecological Economy. No. 10. P.97-100.

Xu, Fuyuan \& He, Jing. (2002). First Study on Supply and Demand Network with Multi-functional and Opening Characteristics for Enterprise. Forecasting. No. 21(6). P.19-22.

Table 1. Comparison of the similarities of SDN and natural ecological system

\begin{tabular}{|c|c|c|c|}
\hline & & Natural ecosystem & SDN artificial ecosystem \\
\hline \multirow{7}{*}{$\begin{array}{l}\text { Structure } \\
\text { similarity }\end{array}$} & Composing factors & $\begin{array}{l}\text { Living beings, with diversity: producers, } \\
\text { reducers, inorganic environment, consumers }\end{array}$ & $\begin{array}{l}\text { SDN enterprises, with diversity: suppliers, } \\
\text { manufacturers, logisticians, management } \\
\text { environment }\end{array}$ \\
\hline & Relationship & $\begin{array}{l}\text { Mutual influence and independence } \\
\text { between factors and environment, and } \\
\text { among factors }\end{array}$ & $\begin{array}{l}\text { Mutual action, influence, and dependence among } \\
\text { SDN enterprises, and between enterprise and } \\
\text { management environment }\end{array}$ \\
\hline & Systems & $\begin{array}{l}\text { Various composing factors form the total } \\
\text { structure of the system according to certain } \\
\text { structure }\end{array}$ & $\begin{array}{l}\text { SDN enterprises form the SDN structure through the } \\
\text { supply and demand relationship }\end{array}$ \\
\hline & Layer & Individual, species group, community & SDN enterprise members, SDN enterprises \\
\hline & Openness & Opening system: energy input, cycle, output & Opening system: resource input, processing, output \\
\hline & Feedback & Positive and negative feedback & Positive and negative feedback \\
\hline & Value structure & Food chain, food network & Innovational value chain, innovational value network \\
\hline \multirow{5}{*}{$\begin{array}{l}\text { Characteristic } \\
\text { similarity }\end{array}$} & Function & $\begin{array}{l}\text { Cycle of matters, energy flow, biology } \\
\text { evolution }\end{array}$ & $\begin{array}{l}\text { Supply and demand flow, information sharing, } \\
\text { collaborative innovation }\end{array}$ \\
\hline & $\begin{array}{l}\text { Environmental } \\
\text { influence }\end{array}$ & Survival of the fittest & Survival of the fittest \\
\hline & Self-organization & $\begin{array}{l}\text { Self-adapting, } \\
\text { self-organization }\end{array}$ & Self-adapting, self-regulation, self-organization \\
\hline & $\begin{array}{l}\text { Dynamic } \\
\text { characteristics }\end{array}$ & Production, development, evolvement & Entering network, development, evolvement \\
\hline & Stability & Evolving continually, dynamically stable & Evolving continually, dynamically stable \\
\hline
\end{tabular}


Table 2. Ecological collaborative innovation model of SDN enterprise

\begin{tabular}{|l|l|l|l|}
\hline $\begin{array}{l}\text { Species } \\
\text { relationship }\end{array}$ & Relationships among species & Relationship among SDN enterprises & $\begin{array}{l}\text { Collaborative } \\
\text { innovation model }\end{array}$ \\
\hline Preying & Species A preys species B & $\begin{array}{l}\text { Enterprise A annexes enterprise B, } \\
\text { belonging to same one enterprise }\end{array}$ & Interior collaboration \\
\hline Competition & $\begin{array}{l}\text { Species A and species B restrict each } \\
\text { other }\end{array}$ & $\begin{array}{l}\text { Homogenous enterprise A and } \\
\text { enterprise B influence each other }\end{array}$ & $\begin{array}{l}\text { Homogenously } \\
\text { strengthening }\end{array}$ \\
\hline Autoeciousness & $\begin{array}{l}\text { It is advantageous to the parasitic } \\
\text { species A, and it may be } \\
\text { advantageous or disadvantageous to } \\
\text { the species B, or influence nothing }\end{array}$ & $\begin{array}{l}\text { Enterprise A depends on the } \\
\text { innovation of enterprise B innovation of enterprise A } \\
\text { The } \\
\text { influences the development of } \\
\text { collaborative enterprise B }\end{array}$ & $\begin{array}{l}\text { Single-direction } \\
\text { dependence } \\
\text { Excluding innovation } \\
\text { Single-direction } \\
\text { dependence }\end{array}$ \\
\hline Intergrowth & $\begin{array}{l}\text { Species A and species B depends } \\
\text { each other and }\end{array}$ & $\begin{array}{l}\text { Heterogeneous enterprise A Aeterogeneous } \\
\text { enterprise B have direct supply and } \\
\text { complementation }\end{array}$ \\
\hline Reciprocal & $\begin{array}{l}\text { Species A and species B are } \\
\text { advantageous to each other }\end{array}$ & $\begin{array}{l}\text { Enterprise A collaboratively } \\
\text { cooperates with enterprise B }\end{array}$ & $\begin{array}{l}\text { Double-direction } \\
\text { interaction }\end{array}$ \\
\hline Laterality & it influences nothing to species B & $\begin{array}{l}\text { The innovation of enterprise B is } \\
\text { advantageous to the collaborative } \\
\text { enterprise A }\end{array}$ & $\begin{array}{l}\text { Single-direction } \\
\text { dependence }\end{array}$ \\
\hline Amensalism & $\begin{array}{l}\text { It is disadvantageous to specials A, } \\
\text { and it influences nothing to species B } \\
\text { A and species B innovation of enterprise B } \\
\text { influences the development of the } \\
\text { collaborative enterprise A }\end{array}$ & $\begin{array}{l}\text { Excluding innovation } \\
\text { Enterprise A has no intersection with } \\
\text { enterprise B }\end{array}$ & $\begin{array}{l}\text { Independent } \\
\text { innovation }\end{array}$ \\
\hline
\end{tabular}

